\title{
Development of Renal Dosing Guidelines: A Prospective Study
}

\author{
Varun Parvathagiri', Aparna Yerramilli², Somasekhar Mudigonda ${ }^{3}$, Swathi Kethavath', \\ Nikitha Rao Yeravalli', Navya Teja Peteti ${ }^{1}$
}

\author{
${ }^{1}$ Pharm.D Interns, Department of Pharmacy Practice, Sri Venkateshwara College of Pharmacy, Madhapur, Affiliated to Osmania \\ University, Hyderabad, INDIA. \\ ${ }^{2}$ Associate Professor, Department of Pharmacy Practice, Sri Venkateshwara College of Pharmacy, Madhapur, Affiliated to Osmania \\ University, Hyderabad, INDIA. \\ ${ }^{3}$ Sr. Consultant Nephrologist, Department of Nephrology, Apollo Hospitals, Jubilee Hills, Hyderabad, INDIA.
}

\begin{abstract}
Background: Patients with Chronic Kidney Disease are at increased risk for potentially harmful prescribing. The selection of appropriate dosing for patients with Chronic Kidney Disease is important to avoid unwanted drug effects, maximize therapeutic efficacy and ensure optimal patient outcomes. Aim: To study the impact of renal dosing guidelines on prescribing pattern in patients with CKD. Methods: This was a prospective, interventional study conducted at a tertiary care centre. In the pre-interventional phase, the case sheets of all the in-patients with CKD with creatinine clearance of $<50 \mathrm{~mL} / \mathrm{min}$ were collected and reviewed for the demographics, lab parameters and medications prescribed. The pre-intervention phase served as the control.As a part of intervention, pocket guides were prepared listing out the drug dosing in renal impairment and were distributed to all clinicians and the patient care areas. In the post-interventional phase, the drug charts were reviewed to observe any improvement in the dosing pattern of renally eliminated drugs. Results: In the pre-intervention study, drug dosing adjustment was needed in 246 drugs where 59 drugs (23\%) were inappropriately dosed. In the post-intervention study, this number was significantly lowered to $23(8 \%)$ drugs out of 284 drugs $(p=0.0001)$ which needed renal dosing. Statistically significant improvements were seen with prescribing of antibiotics $(p=0.0017)$, hypolipidemics $(p=0.0449)$ and antiarrhythmic agents $(p=0.0034)$. Conclusion: The dosing of majority of the renally eliminated drugs followed the recommendations of the package inserts. With the increasing awareness created by the pocket guides, there was a significant improvement in renal dosing. There is a need in health care settings to monitor the use of renally eliminated medications to reduce the adverse effects. The clinical pharmacists in collaboration with clinicians play a significant role in optimizing patient outcomes.
\end{abstract}

Key words: Kidneys, Dose adjustment, Renal failure, Creatinine clearance, Medications.

\section{INTRODUCTION}

Kidney is the major organ for maintaining homeostasis of fluid and electrolytes and in particular, plays an important role in the disposition of many drugs. Chronic kidney disease affects renal drug elimination and other pharmacokinetic processes involved in drug disposition (e.g., absorption, drug distribution, non-renal clearance [metabolism]). About half of all drugs or their metabolites are excreted by the kidneys, and $30 \%$ of all adverse effects of medication have a renal cause or a renal effect. ${ }^{1,2}$

The level of renal function below which the dose of a drug must be reduced depends on how toxic the drug is and whether it is eliminated entirely by renal excretion or is partly metabolized to inactive metabolites. Drug dosing errors are common in patients with renal impairment and can cause adverse effects and poor outcomes. Therefore, severity of Chronic Kidney Disease based on creatinine clearance plays a crucial role in medical management and patients with renal dysfunction must be closely monitored for the drugs that require modifications of dosages or frequencies to prevent adverse effects. Healthcare professionals should be familiar with commonly used medications that require dosage adjustments. ${ }^{3,4}$
DOI: 10.5530/ijopp.9.2.9

\section{Address for} correspondence: Dr. Aparna Yerramilli, Associate Professor, Sri Venkateshwara College of Pharmacy, Madhapur, INDIA. E-mail: svcppharmd.hod@ gmail.com

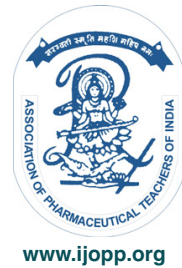


Dosages of drugs cleared renally are based on renal function calculated as Glomerular Filtration Rate (GFR) or Creatinine Clearance $(\mathrm{CrCl})$. Examples of drugs requiring dose adjustment in patients with renal impairment mostly include antibiotics, digoxin, Histamine-2-receptor antagonists, and Angiotensin converting enzyme inhibitors.

This study aims to review the dosing pattern of renally eliminated drugs and develop guidelines for renal dosing of common medications used in the institution.

\section{METHODS}

A prospective, intervention study was conducted at a tertiary care centre, for a period of 6 months (FebruaryJuly 2015) after seeking the approval from the Institutional Ethics Committee (SVCP/2015/27).All adult inpatients $\geq 18$ years with chronic renal dysfunction with creatinine clearance of less than $50 \mathrm{~mL} / \mathrm{min}$ and prescribed with medications that are renally eliminated were included in the study. A structured data collection form was designed to collect the information from the case sheets of the patients. The study was divided into 2 phases, preintervention and post intervention phases. Data regarding the kidney function and the pattern of drug dosing was recorded in the pre intervention phase. Pocket guides were prepared for the drug dosing in renal impairment and were distributed to all clinicians and the patient care areas as a part of intervention. In the post intervention phase, the dosing pattern of renally eliminated drugs was observed for any improvement. The patterns of dosing of renally eliminated drugs were compared in both the phases.

\section{RESULTS AND DISCUSSION}

\section{Pre interventional phase}

In the preinterventionphase, a total of 152 cases were reviewed, 71 of them were nonhemodialysis (Non $\mathrm{HD})$ cases and 81 were undergoing hemodialysis (HD). Majority of patients were male of age group 61-80 years with hypertension as the most common co-morbid condition (Table 1). The number of drugs that required dose adjustments was found to be 246 in which inappropriateness was seen in 59 drugs (23\%). The extent of inappropriate dosing is low in our study compared to the published literature. ${ }^{5,6}$ This may be due to the increased awareness of the clinicians regarding the renal dosing in our setting.

Among the 59 drugs that were dosed inappropriately, majority of drugs were antibiotics. Amikacin, Amoxicllin/ Clavulanate, Imipenem/Cilastatin, Piperacillin/Tazobactum, Valacyclovir, Trimethoprim/Sulfamethoxazole, Cefoperazone/Sulbactum, Bisoprolol, Digoxin were not dosed as per the recommendations. In our study, the inappropriateness rate of antibiotics was $27 \%$, which is similar to the study by Hassan Y et al. ${ }^{5}$ In the same study the rate of inappropriateness in prescribing the cardiovascular medications was $61 \%$, compared to $32 \%$ in our study, a majority being Anti-arrhythmics. The type of dosage adjustments needed were found to be dose reduction in $37 \%$ of the drugs, change of dosing interval in $46 \%$ of the drugs, and about $17 \%$ of the drugs were contraindicated for the prescribing in renal function (Table 3).

As a part of intervention, in our study, pocket guides were prepared for the drug dosing in renal impairment and were distributed to all clinicians and the patient care areas. Various interventions like having a clinical pharmacist on medical rounds and using an integrated computing system to guide appropriate dosing was used in other studies. ${ }^{5,7}$

\section{Post intervention phase}

In this phase, data regarding the dosing of renally eliminated drugs after the distribution of pocket guides were collected. Out of 130 cases studied in the postintervention phase, 75 non hemodialysis cases and 55 hemodialysis cases were reviewed. Majority of patients were male of age group 61-80 years with hypertension as the co-morbid condition (Table 1).

The averagenumber of drugs perprescription was 10 in both the preintervention and postintervention phase. The number of drugs dosed appropriately increased significantly from $75 \%$ in the preintervention phase to $92 \%$ in the post intervention phase. (Table 2) Out of all 284 renally eliminated drugs prescribed in the post-interventional phase, dosing inappropriateness was reported in 23 drugs (8\%). Majority of drugs were antibiotics comprising Imipenem/Cilastatin, Amoxicillin/Clavulanate and Cefoperazone/Sulbactum. In our study, the inappropriateness rate of antibiotics in postintervention was $10 \%$. The rate of inappropriateness in prescribing the cardiovascular medication was $16 \%$, where antiarrhythmics constituting a larger rate of inappropriateness, which is similar to the pre-intervention phase. The type of dosage adjustments needed were found to be dose reduction in $35 \%$ of the drugs, change of dosing interval in $30 \%$ of the drugs, and about $35 \%$ of the drugs were contraindicated for the prescribing in renal function (Table 3).

By comparing the results of post and pre intervention phases, it is clear that there is a significant impact of the dosing guidelines in the form of pocket guides in improving the dosing pattern of the renally eliminated drugs. The rate of inappropriateness in dosing was significantly reduced in the overall prescriptions from $23 \%$ to $8 \%(\mathrm{p}=0.0001)$, in antibiotics category from $27 \%$ to $10 \%$ 
Table 1: Demographic profile of study population

\begin{tabular}{|c|c|c|c|c|}
\hline \multirow{3}{*}{$\begin{array}{c}\text { Demographics } \\
\text { Gender }\end{array}$} & \multirow{2}{*}{\multicolumn{2}{|c|}{$\begin{array}{l}\text { PRE-INTERVENTION } \\
\text { No of patients }(n=152)\end{array}$}} & \multirow{2}{*}{\multicolumn{2}{|c|}{$\begin{array}{l}\text { POST-INTERVENTION } \\
\text { No. of patients }(n=130)\end{array}$}} \\
\hline & & & & \\
\hline & Non HD (71) & HD (81) & Non HD (75) & HD (55) \\
\hline Female & $29(41 \%)$ & $30(37 \%)$ & $21(28 \%)$ & $22(40 \%)$ \\
\hline Male & $42(59 \%)$ & $51(63 \%)$ & $54(72 \%)$ & $33(60 \%)$ \\
\hline \multicolumn{5}{|l|}{ Age Groups (in years) } \\
\hline $18-40$ & $8(11.26 \%)$ & $12(14.8 \%)$ & $6(8 \%)$ & $10(18.2 \%)$ \\
\hline $41-60$ & $26(36.62 \%)$ & $31(38.2 \%)$ & $25(33.33 \%)$ & $24(43.64 \%)$ \\
\hline $61-80$ & $34(47.88 \%)$ & $36(44.48 \%)$ & $43(57.3 \%)$ & $20(36.36 \%)$ \\
\hline$>80$ & $3(4.22 \%)$ & $2(2.4 \%)$ & $1(1.33 \%)$ & $1(1.8 \%)$ \\
\hline Age: Mean+SD (Median) & $61+14.83(61)$ & $57+15.19(57)$ & $62.27+12.75(65)$ & $55.64+15.96(57)$ \\
\hline \multicolumn{5}{|c|}{ Co-morbid conditions } \\
\hline $\mathrm{BPH}$ & 2 & 1 & 2 & 0 \\
\hline CAD, LV dysfunction & 12 & 8 & 12 & 8 \\
\hline Diabetes mellitus & 17 & 16 & 18 & 19 \\
\hline Hypertension & 22 & 31 & 23 & 31 \\
\hline Electrolyte imbalances & 2 & 0 & 2 & 3 \\
\hline Infections & 14 & 3 & 18 & 6 \\
\hline Liver diseases & 2 & 1 & 4 & 4 \\
\hline Thyroid disorders & 0 & 0 & 2 & 3 \\
\hline \multicolumn{5}{|c|}{ Serum Creatinine } \\
\hline Mean+SD (Median) & $2.9+1.65(2.3)$ & $8.1+4.45(6.9)$ & $2.2+0.9(1.9)$ & $8.1+4.27(6.9)$ \\
\hline
\end{tabular}

BPH-Benign Prostatic Hyperplasia, CAD-Coronary Artery Disease, LV-Left Ventricular.

Table 2: Number of medications prescribed in study population

\begin{tabular}{|c|c|c|c|c|}
\hline \multirow{2}{*}{ Category } & \multicolumn{2}{|c|}{ PRE-INTERVENTION } & \multicolumn{2}{|c|}{ POST-INTERVENTION } \\
\hline & Non HD & HD & Non HD & HD \\
\hline Total number of prescriptions & 71 & 81 & 75 & 55 \\
\hline Total number of drugs prescribed & 756 & 913 & 742 & 590 \\
\hline Average number of drugs per prescription & 10.65 & 11.27 & 9.9 & 10.73 \\
\hline Number of drugs that require dose adjustment in renal failure & 110 & 136 & 166 & 116 \\
\hline Number of drugs dosed appropriately & $83(75.5 \%)$ & $104(76.5 \%)$ & $152(91.6 \%)$ & $107(92.2 \%)$ \\
\hline Number of drugs dosed inappropriately & $27(24.5 \%)$ & $32(23.5 \%)$ & 14 (8.4\%) & $9(7.8 \%)$ \\
\hline
\end{tabular}

Table 3: Details of type of dosing adjustment needed

\begin{tabular}{ccc}
\multirow{2}{*}{ Type of adjustment } & PRE-INTERVENTION & POST-INTERVENTION \\
\cline { 2 - 3 } & No. of drugs $\mathbf{n = 5 9}(\%)$ & No. of drugs $\mathbf{n = 2 3}(\%)$ \\
\hline Dose reduction & $22(37)$ & $8(35)$ \\
Change in dosing interval & $27(46)$ & $7(30)$ \\
Contraindicated/ not recommended & $10(17)$ & $8(35)$ \\
\hline
\end{tabular}




\begin{tabular}{|c|c|c|c|c|c|}
\hline \multirow[t]{2}{*}{ Parameters } & \multicolumn{2}{|c|}{ Pre intervention } & \multicolumn{2}{|c|}{ Post intervention } & \multirow[t]{2}{*}{ p value* } \\
\hline & Total, N=246 & $\begin{array}{c}\text { Inappropriate, } \\
\mathbf{n}(\%)\end{array}$ & $\begin{array}{l}\text { Total, } \\
\mathrm{N}=284\end{array}$ & $\begin{array}{c}\text { Inappropriate, } \\
\text { n (\%) }\end{array}$ & \\
\hline $\begin{array}{l}\text { No. of Drugs requiring } \\
\text { renal dosing }\end{array}$ & 246 & $59(23)$ & 284 & $23(8)$ & 0.0001 \\
\hline Antibiotics & 90 & $24(27)$ & 112 & $11(10)$ & 0.0017 \\
\hline Analgesics & 50 & $3(6)$ & 25 & 0 & NS \\
\hline Anti hypertensives & 34 & $6(18)$ & 11 & $2(18)$ & NS \\
\hline Anti convulsants & 10 & $2(20)$ & 10 & 0 & NS \\
\hline Anti-coagulants & 20 & $2(10)$ & 25 & 0 & NS \\
\hline Hypolipidemics & 9 & $4(44)$ & 20 & $2(10)$ & 0.0449 \\
\hline Anti-ulcers & 7 & $2(29)$ & 1 & 0 & NS \\
\hline Anti arrhythmics & 6 & $6(100)$ & 18 & $5(28)$ & 0.0034 \\
\hline Anti fungals & 5 & $1(20)$ & 15 & $1(7)$ & NS \\
\hline Anti virals & 5 & $3(60)$ & 1 & 0 & NS \\
\hline CNS agents & 5 & $3(60)$ & 0 & 0 & NS \\
\hline Anti diabetics & 3 & $2(67)$ & 1 & 0 & NS \\
\hline Anti tubercular & 1 & $1(100)$ & 3 & 0 & NS \\
\hline Anti gout & 1 & 0 & 1 & 0 & NS \\
\hline Miscellaneous & 0 & 0 & 13 & $2(15)$ & NS \\
\hline
\end{tabular}

* $\chi^{2}$ test for association between two qualitative variables

$p$ value $<0.05-$ statistically significant, NS-not significant.

$(\mathrm{p}=0.0017)$, hypolipidemics category from $44 \%$ to $10 \%$ $(p=0.0449)$ (Table 4). Similarly, the rate of inappropriateness in dosing was reduced in other categories of drugs like anti hypertensives, analgesics, antiulcer agents, antiarrhythmics, antianginals etc.

\section{LIMITATIONS}

Dosing of medications in patients undergoing continuous renal replacement therapy was not studied due to the small population on Continuous Renal Replacement Therapy (CRRT). Significant improvement in the prescription pattern of some category of medications was not observed as the medications were prescribed not only on the basis of renal function but also on the patient's response.

\section{CONCLUSION}

The prevalence of Chronic Kidney Disease is increasing and polypharmacy is common. Hence, there is a need to monitor the dosing of drugs in those patients to avoid the adverse effects, to reduce the length of stay in the hospital and to control the unnecessary cost of medications. Development of renal dosing guidelines for patients hospitalized with CKD can improve the pattern of prescribing in renal failure population. This study aptly signifies that clinical pharmacists in association with physicians play an essential role in optimizing the patient health care.

\section{ACKNOWLEDGEMENTS}

We express our gratitude to all those who contributed in many ways to the success of this study. We are extremely indebted to Dr. Sanjay Maitra, Dr. Ravi Andrews, Consultant Nephrologists; Dr. Sanjeev Sharma, Clinical Pharmacologist, Apollo Hospital, Jubilee Hills, Hyderabad for providing continuous guidance all through this project. We are also thankful to Principal Dr. Bhagavan Raju and Management of Sri Venkateshwara College of Pharmacy for supporting us throughout the study.

\section{CONFLICT OF INTEREST}

The author declare no conflict of interest.

\section{ABBREVIATIONS USED}

None.

\section{Funding: Nil}

\section{REFERENCES}

1. Aronoff GR, Bennett WM, Berns JS, Brier ME.2007. Drug prescribing in renal failure: Dosing guidelines for Adults, $5^{\text {th }}$ edition. American College of Physicians, Philadelphia, Pa. 
2. Joseph TD, Robert LT, Gary CY, Gary RM. Pharmacotherapy - A pathophysiologic approach; McGraw Hill Publications, Chicago. $7^{\text {th }}$ edition. Chronic Kidney Disease. 745-800.

3. Hassan Y, Al-Ramahi RJ, Aziz NA, Ghazali R.Drug Dosing Adjustments in Patients with Chronic Kidney Disease. Ann Acad Med Singapore. 2009.38(12):1095-103.

4. Gabardi S, Abramson S. Drug dosing in CKD. Med Clin N Am. (2005);89(3); 649-87.
5. Hassan Y, Al-Ramahi RJ, Aziz NA, Ghazali R. Impact of a renal drug dosing service on dose adjustment in hospitalized patients with CKD. Ann of Pharmacother. 2009. 10.1345/aph.1M187.Epub.2009;43(10):1598-605.

6. Salomon L, Deray G, Jaudon MC. Medication misuse in hospitalized patient with renal impairment. Int J Qual Health Care. 2003; 15(4):235-240.

7. Chertow G M, Joshua Lee, Gilad JK, Elisabeth B. Guided Medication Dosing for Inpatients with Renal Insufficiency. JAMA December 12. 2001;286(22):2839-44. 